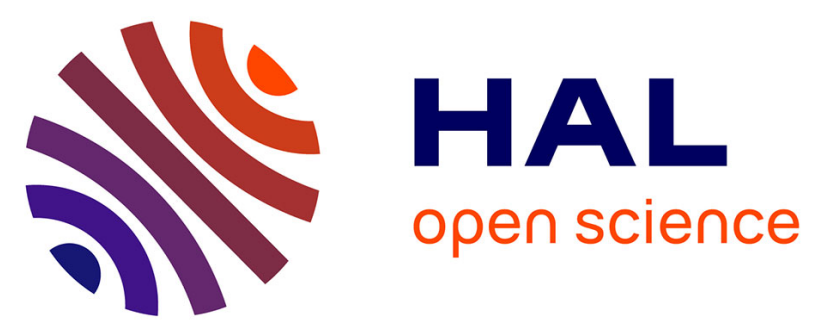

\title{
Probing the influence of cell surface polysaccharides on nanodendrimer binding to Gram-negative and Gram-positive bacteria using single-nanoparticle force spectroscopy
}

Audrey Beaussart, Christophe Beloin, Jean-Marc Ghigo, Marie-Pierre Chapot-Chartier, Saulius Kulakauskas, Jérôme D.F. Duval

\section{To cite this version:}

Audrey Beaussart, Christophe Beloin, Jean-Marc Ghigo, Marie-Pierre Chapot-Chartier, Saulius Kulakauskas, et al.. Probing the influence of cell surface polysaccharides on nanodendrimer binding to Gram-negative and Gram-positive bacteria using single-nanoparticle force spectroscopy. Nanoscale, 2018, 10 (26), pp.12743 - 12753. 10.1039/c8nr01766b . pasteur-01875323

\section{HAL Id: pasteur-01875323}

https://hal-pasteur.archives-ouvertes.fr/pasteur-01875323

Submitted on 7 Feb 2022

HAL is a multi-disciplinary open access archive for the deposit and dissemination of scientific research documents, whether they are published or not. The documents may come from teaching and research institutions in France or abroad, or from public or private research centers.
L'archive ouverte pluridisciplinaire HAL, est destinée au dépôt et à la diffusion de documents scientifiques de niveau recherche, publiés ou non, émanant des établissements d'enseignement et de recherche français ou étrangers, des laboratoires publics ou privés.

\section{(ㄷ)(1) $\$$}

Distributed under a Creative Commons Attribution - NonCommerciall 4.0 International 
Probing the influence of cell surface polysaccharides on nanodendrimer binding to Gram-negative and Gram-positive bacteria using singlenanoparticle force spectroscopy

\footnotetext{
Audrey Beaussart ${ }^{1 *}$, Christophe Beloin ${ }^{2}$, Jean-Marc Ghigo ${ }^{2}$, Marie-Pierre Chapot-Chartier $^{3}$, Saulius Kulakauskas ${ }^{3}$, and Jérôme F.L. Duval ${ }^{1}$
}

1 Université de Lorraine, CNRS, LIEC, F-54000 Nancy, France.

2 Institut Pasteur, Unité Génétique des Biofilms, F-75724 Paris 15, France.

3 Micalis Institute, INRA, AgroParisTech, Université Paris-Saclay, 78350 Jouy-en-Josas, France.

* Corresponding author:

A. Beaussart: audrey.beaussart@univ-lorraine.fr 
TABLE OF CONTENTS ENTRY

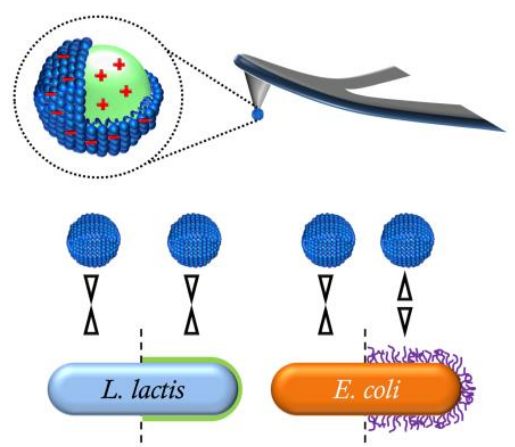

Interaction forces between a zwitterionic nanodendrimer and bacterial surfaces are assessed at the single cell/nanoparticle pair level. 


\section{Abstract}

The safe use and design of nanoparticles (NPs) require a comprehensive interpretation of their potentially adverse effects on (micro)organisms. In that respect, the prior assessment of the interactions experienced by NPs in the vicinity of - and in contact with - complex biological surfaces is mandatory. It requires the development of suitable techniques for deciphering the processes that govern nano-bio interactions at the single NP/organism pair level. Here, we used atomic force spectroscopy (AFM)-based force measurements to investigate at the nanoscale the interactions between carboxylateterminated polyamidoamine (PAMAM) nanodendrimers and two bacteria with very distinct properties, Escherichia coli and Lactococcus lactis. The nanodendrimers exhibit a negative peripheral surface charge and/or a positive intraparticulate core depending on solution $\mathrm{pH}$ and salt concentration. Following an original strategy according to which a single dendrimer NP is grafted at the very apex of the AFM tip, the density and localization of NP binding sites are probed at the surface of E. coli and L. lactis mutants expressing different cell surface structures (presence/absence of O-antigen of the lipopolysaccharides (LPS) or polysaccharide pellicle). In line with electrokinetics, AFM force measurements evidence that adhesion of NPs on pellicle-decorated L. lactis is governed by their underlying electrostatic interactions as controlled by the $\mathrm{pH}$-dependent charge of the peripheral and internal NP components, and the negatively-charged cell surface. In contrast, the presence of O-antigen on E. coli systematically suppresses the adhesion of nanodendrimers to cells, may the effective NP charge be determined by the peripheral carboxylate groups or by the internal amine functions. Altogether, this work highlights the differentiated roles played by surface polysaccharides in mediating NPs attachment to Gram-positive and Gram-negative bacteria. It further demonstrates that the assessment of NPs bioadhesion features requires a critical 
analysis of the electrostatic contributions stemming from the various structures composing the stratified cell envelope, and those originating from the bulk and surface NPs components. In that respect, the joint use of electrokinetics and AFM provides a valuable option for rapidly addressing the binding propensity of NPs to microorganisms, as urgently needed in NPs risk assessments.

\section{Introduction}

Engineered soft nanoparticles (NPs) have rapidly emerged in pharmaceutical and biomedical applications due to the versatility of options they offer in terms of chemical and physical functionalities. ${ }^{1}$ Rationalizing NPs design is essential to meet the best compromise between performance for a given targeted purpose (e.g. diagnosis, drug delivery) and reduction of the bioadverse outcomes they may generate for humans and/or (micro)organisms once released in the environment at the end of their life cycle. ${ }^{2}$ Providing a clear connection between NPs structure/composition and their toxicity is not a trivial task due to the complexity of the mechanisms that take place at bio-nano interfaces. ${ }^{3}$ In order to address such a connection at a mechanistic level, it is essential to first evaluate the type and magnitude of interaction forces between NPs and cell envelopes, the latter being known to confer/maintain cell shape, regulate internal turgor pressure or mediate (bio)adhesion. These interactions are determined by the physico-chemical surface/bulk properties of the NPs, the nature and density of biomolecules distributed over the cell surface (e.g. proteins, polysaccharides) and by the medium conditions (e.g. $\mathrm{pH}$, salinity, temperature) that impact on the NPs-cell surface encounter rate. 
Representative examples of manufactured soft nanoparticles include (nano)dendrimers defined by an internal hyperbranched structure supporting amine charges and a peripheral layer whose composition can be tailored at will. ${ }^{4,5}$ (Nano)dendrimers are now routinely employed in diverse technologies and fields such as catalysis, material science and biology/medicine, where they serve e.g. as imaging agents, antimicrobial compounds or drug carriers. $^{6-10}$ These particles are further suitable model systems to mimic environmental colloids that often consist of a core component surrounded by (bio)macromolecules or proteinaceous corona. ${ }^{11-13}$ Despite the numerous functions dendrimers may offer, ${ }^{14}$ their use is now debated following recent reports that evidence their potential cytotoxicity. In particular, they have been reported to favor cytotoxic and hemolytic actions due to the diversity of their targets, such as plasma membranes, ${ }^{15}$ cell organelles (e.g. endosome, ${ }^{16}$ mitochondria, ${ }^{17,18}$ nucleus) ${ }^{19}$ and proteins such as enzymes. ${ }^{20}$ The toxicity of full-generation cationic dendrimers has been mostly attributed to the interactions they generate with anionic cell membranes. The use of half-generation dendrimers carrying anionic peripheral groups was then suggested as an alternative to prevent attraction of such NPs to cells and therewith their subsequent ad/ab-sorptions on cell membranes. ${ }^{2}$ In line with this reasoning, studies conducted in vivo with anionic dendritic NPs reported a toxicity that was less pronounced than that generated by their full generation counterparts. ${ }^{21,22}$ However, as demonstrated in our recent work, ${ }^{23}$ the sign of the effective charge of 'anionic' NPs with negative surface charge and positively charged inner core may change under slight modification of $\mathrm{pH}$ and salinity of the dispersing medium. ${ }^{23,24}$ In turn, a prediction of dendrimer toxicity towards (micro)organisms requires a full account not only of the physicochemical NPs surface features but also of those defining the NP bulk composition, both 
mediating -together with the biophysical properties of the membrane- the NP-cell interactions under aqueous conditions.

Well-studied and genetically amenable model bacteria represent suitable and controlled systems to address NPs interactions with their envelopes. The distinct structures and compositions of Gram-negative and Gram-positive bacterial surfaces have been reported to interact differently with NPs. ${ }^{25-29}$ In particular, Gram-negative bacterial LPS and Grampositive bacterial teichoic acids are among the major biomolecules that possibly influence nanotoxicity as their presence/structure largely modulate bacteria-NPs interactions..$^{30-35}$ Moreover, the use of genetic engineering allows an additional level of controlled investigation of bacterial-NPs interaction via selective over-expression of genes encoding surface molecules or structures such as fimbriae, pili or LPS that inherently mediate the interactions of the whole cell with its surrounding environment. ${ }^{36}$ Even though the initial interplay between NPs and surface polysaccharides is a recognized important step for adequate NPs risk assessment, the evaluation of NPs binding to cell envelopes at the relevant nanometric scale has received scant attention so far. This is mainly explained by a lack of appropriate techniques able to probe bio-physicochemical interactions involving NPs at the relevant single cell and single NP levels.

Atomic force microscopy and related single-molecule force spectroscopy have opened up new possibilities to assess bio-nano association mechanisms down to the molecular scale. ${ }^{37}$ In this work, adopting an original strategy to decorate AFM tips with carboxylate-terminated polyamidoamine nanodendrimers (COOH-PAMAM), we demonstrate for the first time the performance of AFM-single NP force spectroscopy for addressing the differentiated adhesion of single NP to Gram-positive and Gram-negative bacteria, L. lactis and E. coli, 
respectively, genetically modified to express or not surface polysaccharides. Using independent electrophoretic mobility measurements performed on bacteria and NPs, we also show that NPs binding to the cell surface is predominantly driven by electrostatic interactions, and that NP adhesion features are strongly mediated by both the polymeric biomolecules carried by the bacteria and the composition of the supporting cell wall structure.

\section{Results and discussion}

\section{Bacterial cell surface imaging.}

The surface morphology of the bacteria of interest in this work was first imaged in a $10 \mathrm{mM} \mathrm{KNO}_{3}$ background electrolyte using AFM (Figure 1). To do so, living cells were immobilized on porous membranes and imaged in contact mode upon application of a low force $(\sim 100 \mathrm{pN})$ to preserve cell surface structure integrity. Representative deflection images of E. coli wild type (WT) and its mutant derivative genetically modified to express O-antigen at their surface $\left(E \text {. coli } \mathrm{LPS}^{+}\right)^{38}$ are provided in Figure 1 together with results pertaining to WT L. lactis and to L. lactis mutants lacking their native surface polysaccharide pellicle (L. lactis PSP $^{-}{ }^{39}$ WT E. coli cell surface is smooth and featureless both at the cell pole (Fig. 1a top) and on the side wall (Fig. 1a bottom). By contrast, E. coli PPS $^{+}$are rougher and exhibit distinguishable strikes (Fig. 1b) possibly due to an alteration of the cell surface upon scanning, a finding that is consistent with the presence of a flexible O-antigen layer at the bacterial surface. As far as L. lactis cells are concerned, no major differences in cell surface features could be seen on the images for the WT and modified L. lactis PSP ${ }^{-}$strains. However, roughness analysis revealed that the WT strain is slightly smoother $(\mathrm{Rq}=0.54 \mathrm{~nm}$ 
on $400 \mathrm{~nm} \times 400 \mathrm{~nm}$ area) than the PSP $^{-}$mutant ( $\mathrm{Rq}=1.2 \mathrm{~nm}$ on $400 \mathrm{~nm} \times 400 \mathrm{~nm}$ area), most likely due to the disappearance of the polysaccharidic outer layer and exposure of the peptidoglycan layer on $\mathrm{PSP}^{-}$strain, in correlation with previously reported observations. ${ }^{39,40}$ Both cell types are marked by a well-defined division septum (Figs. 1c-1d, white arrows) and characteristic ring-like structures located at a certain distance from the septum (Figs. 1c-1d, red arrows). In agreement with previous suggestions from literature, ${ }^{40,41}$ these structures most likely define the position of the division site and are reminiscent of other Gram-positive bacteria such as streptococci or staphylococci. ${ }^{41,42}$

\section{Electrokinetics of bacteria and G8.5 PAMAM-COOH dendrimers.}

In this section, we address the impact of solution $\mathrm{pH}$ on the electrostatic features of the here-adopted bacterial interphases and G8.5 PAMAM-COOH dendrimers. Figs. 2a-2b display the dependence of the electrophoretic mobility $\mu$ of the four bacterial strains of interest on the concentration of $\mathrm{KNO}_{3}$ electrolyte at $\mathrm{pH} 6.0$ (Fig. 2a) and $\mathrm{pH} 3.5$ (Fig. 2b). At pH 6.0, $\mu$ is negative for all strains and it decreases (in absolute value) with increasing background electrolyte concentration as a result of significant cell charge screening. At $\mathrm{pH} \mathrm{3.5,} \mathrm{this}$ dependence of $\mu$ on salt concentration is basically maintained for all strains. In addition, a significant decrease in $|\mu|$ is observed at low salt concentrations for L. lactis PSP $^{-}$with decreasing $\mathrm{pH}$ from 6 to 3.5, whereas $\mu$ for E. coli WT and L. lactis WT cells remains quasiindependent of solution $\mathrm{pH}$ over the whole range of salinity conditions investigated. The striking feature is the nearly zero mobility of $E$. coli $\mathrm{LPS}^{+}$at $\mathrm{pH}$ 3.5. The results obtained at $\mathrm{pH}$ 6 and $\mathrm{pH} 3.5$ versus salt concentration for $E$. coli WT and L. lactis WT cells are qualitatively in line with the generic electrokinetic properties expected for bacteria ${ }^{43,44}$ and the protolytic features of their major ionogenic surface sites. In details, the negative charge in WT L. lactis 
originates from the phosphate groups contained in the phosphodiester bonds that link the hexasaccharide repeating units of the pellicle. ${ }^{39}$ In the absence of pellicle, the charges most likely stem from the D-Asp residues of the PG interpeptide crossbridge ${ }^{45}$ or the presence of residual lipoteichoic acids (LTA) at the cell surface. ${ }^{46,47}$ The results obtained for E. coli LPS $^{+}$ highlight the peculiar physico-chemical cell surface properties conferred by the O-antigen LPS component and absent in E. coli WT strain. LPS include three components: the lipid A, the core oligosaccharide and the O-antigen, the latter forming the outermost layer of the cell envelope (schematic Fig. 1b). O-antigen mostly comprises repeats of 3 - to 8-sugar units. $^{48}$ The E. coli LPS $^{+}$strain used in this work (MG1655 wbbL restored) is 016, and therefore is composed of 5 -sugar units repeats. ${ }^{48}$ The negative charge carried by $E$. coli is conferred by the ester-linked phosphate groups within the lipid A region, as well as the carbonyl groups of KDO and phosphate groups of phosphorylated sugars of the core. ${ }^{49,50}$ However, the O-antigen is made up of hydrophilic sugar residues which tend to be uncharged, therefore acting as a barrier that shields the apparent negative charge carried by the bacteria. ${ }^{51-54}$ In the current study, the shielding effect is particularly pronounced at $\mathrm{pH}$ 3.5, where the presence of the $\mathrm{O}$-antigen totally cancels out the negative charge within the lipid A and core layer of E. coli. Altogether, the electrokinetic signatures depicted in Fig. 2 highlight the significant modulation of the overall defining electrostatic properties of bacterial cell surfaces according to both their cell envelope structure (Gram-negative $E$. coli vs Gram-positive L. lactis) and the nature of their polysaccharidic decoration (O-antigen vs pellicle).

Additionally we measured the electrokinetic properties of carboxylate-terminated polyamidoamine dendrimer NPs (PAMAM- $\mathrm{COOH}$, generation 8.5 ) under the $\mathrm{pH}$ and salinity conditions adopted in Fig. 2 (Fig. 3). PAMAM-COOH dendrimers are soft (i.e. ion/water 
permeable) NPs consisting of a hyperbranched amino-core with protonable tertiary amine groups and of a peripheral surface layer, the locus of dissociable carboxylic groups (Fig. 4). Fig. 3 highlights the salt-mediated screening of the effective charge carried by dendrimer NPs, especially at $\mathrm{pH} 3.5$, and it further evidences a change in the sign of the electrophoretic mobility $\mu$ of G8.5 PAMAM-COOH dendrimers with increasing $\mathrm{pH}$ from 3.5 to 6.0 . As extensively detailed in a preceding report PAMAM-COOH electrokinetics is dominated at $\mathrm{pH}$ 3.5 by intraparticulate protonated tertiary amine groups which leads to positive $\mu$ regardless of salt concentration. ${ }^{23}$ In contrast, the carboxylic groups located in the peripheral dendrimer shell are nearly completely dissociated at $\mathrm{pH} 6.0$, which originates negative NP mobility under such $\mathrm{pH}$ conditions. The reader is referred to previous publication by the authors for further details on the electrohydrodynamic features of such G8.5 PAMAM dendrimers that display interfacial zwitterionic functionality. ${ }^{23}$

\section{AFM force spectroscopy measurements.}

In light of the above ensemble-averaged electrokinetic properties identified for dispersions of PAMAM-COOH dendrimer NPS, E. coli and L. lactis bacteria, it is anticipated that the adhesion of dendrimer NPs to the microorganisms is governed -at least partially- by electrostatic interactions that should differ from one bacterium to another depending on their cell envelope composition and structure. To test this hypothesis at the relevant nanometric scale, the adhesion forces between G8.5 PAMAM dendrimers and the surface of the (living) bacteria of interest were measured using AFM-based force spectroscopy. To do so, PAMAM NPs were covalently grafted on the AFM tips via the amino-carboxy linking chemistry detailed in the Methods section, resulting in the attachment of a single NP at the apex of the tip (Fig. 4a) ${ }^{23}$. Working in so-called force-volume mode, ${ }^{55,56}$ a virtual mesh of $32 \mathrm{x}$ 
32 pixels (which corresponds to $500 \mathrm{~nm} \times 500 \mathrm{~nm}$ surface area) was created at the cell surface (illustrated in Fig. 4b), where approach and retract curves were then recorded in each pixel (Fig. 4c). This allows the establishment of a spatial mapping of the interaction force between dendrimer NP and bacterial surfaces. In details, the approach regime (Fig. 4c, blue curve) allows to sense long range electrostatic interactions between the two entities before contact is established. After contact, the retraction regime (Fig. 4c, black curve) permits to decipher whether the NP bound to the bacterial cell-wall, and to evaluate the adhesion force required to detach the NP from the biosurface and the (possible) unfolding of the biomolecules involved in the interaction. The obtained adhesion maps, adhesion-force histograms (derived from the retraction force measurements, Fig. 4c) and the representative force-distance curves as measured in $10 \mathrm{mM} \mathrm{KNO}_{3}$ electrolyte concentration at $\mathrm{pH} 6$ between G8.5 dendrimer PAMAM-COOH NP and the 4 bacterial strains of interest in this study are reported in Fig 5. For all bacterial strains examined, most of the approach curves reflect a repulsive NP-bacterium interaction profile (Fig. 5, blue curves) and the percentage of non-adhesive events detected upon retraction of the NP-decorated tip from the cell surface is very high (> 98\%; Fig. 5, black curves). At pH 6, the effective surface charge carried by the NPs is systematically negative (Fig. 3, shaded area) and so is the charge of the bacterial cell surfaces (Fig. 2a). The repulsion evidenced by AFM-single NP force measurements supports that electrostatics prevent attachment of the NPs at the microbial surfaces under such $\mathrm{pH}$ condition.

We also determine adhesion maps, adhesion force-histograms and representative forcedistance curves obtained when dendrimers interact with the bacterial cells at $\mathrm{pH} 3.5$ in 10 $\mathrm{mM}$ electrolyte concentration (Fig. 6). Contrary to the situation previously detailed, measurements now reveal a high frequency of dendrimer NP-L. lactis WT adhesion events 
on the retraction curves ( 53 to $55 \%$ ) with adhesion forces ranging from $100 \mathrm{pN}$ to $500 \mathrm{pN}$ (Fig. 6a). Two types of force-distance curves profiles may be distinguished: (i) profiles with a marked single adhesion peak observed upon retraction of the NP-decorated tip in the continuity of the linear compliance region (with therefore no sign of surface biocompounds extension, Fig. 6a, top force curve), and (ii) profiles with adhesion peaks detected at bacteria to NP separation distances reminiscent of proteins/polysaccharides unfolding (Fig. 6a, bottom force curve). These findings suggest that the interactions between positivelycharged NP and the negatively charged surface of L. lactis WT (Figs. 2 and 3) are primarily mediated by attractive electrostatics, in line with the sign of the force measured in the approach phase, and that they involve the binding to and unfolding of biomolecules at the cells surface. Closer inspection of the adhesion force-maps further reveals that NP-cell binding sites are non-homogenously distributed over the cell surface and form clusters or patches. This may indicate that i) the polysaccharidic pellicle does not form a monolayer at the surface of L. lactis, ii) the pellicle is heterogeneous in composition and NPs bind differently to the different pellicle-constituting polysaccharides, and/or that iii) NPs bind to surface biomolecules other than those stemming from the bacterial pellicle. At this stage, it is worth mentioning that AFM imaging revealed a homogeneous pellicle layer (Fig. 1c) reported to form a compact and continuous cell surface structure composed of polysaccharide made of hexasaccharide repeating units (containing two glucoses (Glc), two N-Acetylglucosamine (GlcNAc), one Rhamnose (Rha), and one D-Galactose (Galf)) residues linked via phosphodiester bonds. ${ }^{39}$ With these latter elements in mind, it is most likely that the density of the L. lactis surface pellicle does not allow binding of the NP to compounds underneath the layer, and that the observed adhesive patches are due to NPs anchoring sites heterogeneously distributed within the polysaccharidic layer. In other terms, this 
means that either the secreted polysaccharides are localized as patches and totally absent at some surface spots, or that there are present all over the cell but in various proportions. A high level of adhesive events was also detected at the surface of L. lactis PSP' (38 to $68 \%$, Fig. 6b). In the absence of the peripheral pellicle, the NP certainly binds to bacterial surface via electrostatic interactions between the positively-charged dendrimer and the surface biocompounds carrying a negative charge conferred either by the interpeptide crossbridges of PG or the presence of LTA. Another hypothesis would be that the NPs bind to the recentlydiscovered rhamnan polysaccharide trapped inside the PG and exposed the cell surface in absence of PSP. ${ }^{57}$ However, the homogeneous distribution of the binding events on the map Fig. $6 \mathrm{~b}$ and the shape of the retraction force-distance curves (with no sign of biomolecules unfolding) strongly suggest that the NPs interact with an homogeneous rigid surface compound that does not unfold under external applied force, most likely the PG. The magnitude of the adhesion forces (ranging from 50 to $200 \mathrm{pN}$ for L. lactis PSP' as compared to 100 to $500 \mathrm{pN}$ for L. lactis WT) qualitatively correlates with the values of $|\mu|$ measured at $\mathrm{pH} 6$ for these two strains $\left(0.92\right.$ and $2.62 \times 10^{-8} \mathrm{~m}^{2} \mathrm{~V}^{-1} \mathrm{~s}^{-1}$ for L. lactis PSP $\mathrm{P}^{-}$and L. lactis WT, respectively). This ensemble of results strongly suggest that the pellicle surface structure does not govern on its own but rather mediates the interaction between the positivelycharged NPs and the cell wall as a whole, most probably by increasing the effective negative charge carried by the bacterial envelope and 'experienced' by the NP when in the vicinity of or in contact with- the cell surface.

The adhesion features of dendrimer NPs on the surface of E. coli WT are shown in Fig. 6c at $\mathrm{pH} 3.5$ and $10 \mathrm{mM}$ electrolyte concentration. The frequency of detected adhesion events ranges from 12 to $36 \%$ with adhesion forces in the $50 \mathrm{pN}-250 \mathrm{pN}$ range. Whereas the electrophoretic mobility of E. coli WT is basically similar to that of L. lactis WT under the 
here-examined $\mathrm{pH}$ condition, the adhesion of dendrimer NPs to the former cell surface type is significantly lower. This result demonstrates that the magnitude of the interactions between charged NPs and Gram-positive or Gram-negative microorganisms cannot generally be derived on the sole basis of their respective surface charges obtained from electrokinetic measurements. Instead, the analysis should necessarily integrate the contributions from the respective components of the cell envelope, that is the oligosaccharidic core and lipid $A$ anchored in the outer lipid membrane for Gram-negative E. coli, and the exposed peptidoglycan covered by pellicle for the Gram-positive L. lactis. Contrary to E. coli WT cells, repulsive force-distance profiles are measured at $\mathrm{pH} 3.5$ with approaching NP-functionalized tip toward the surface of E. coli $\mathrm{LPS}^{+}$(Fig. 6d, blue curves), and no NP-E. coli $\mathrm{LPS}^{+}$adhesion events could be detected in the retraction stage (Fig. 6d, black curves). These findings are qualitatively consistent with the quasi-neutral charge carried by E. coli $\mathrm{LPS}^{+}$at $\mathrm{pH} 3.5$ (Fig. 2) and the positive (effective) charge carried by dendrimers under such $\mathrm{pH}$ conditions. In agreement with literature, this result confirms that expression of the $\mathrm{O}$-antigen part of the LPS leads to a complete neutralization of the negative charge carried by the supporting cell envelope of $E$. coli and it emphasizes the importance of surface polysaccharides in mediating NPs/microorganism interactions. In addition, the presence of the flexible O-antigen LPS layer likely leads to a significant repulsive entropic contribution to the overall NP- E. coli LPS $^{+}$ interaction Gibbs energy, thereby preventing adhesion of NPs to the cell envelope, regardless of the $\mathrm{pH}$-dependent effective charge it carries (which translates into the quasi total absence of adhesion events on the map Fig. 6d). 


\section{Conclusions}

Cell surface polysaccharides have been suggested as important contributors to the attachment/adhesion of NPs to bacteria. In this study, electrokinetics and single-NP force spectroscopy are employed to address the interaction forces acting between PAMAM-COOH G8.5 dendrimer NP and the surface of Gram-positive L. lactis and Gram-negative E. coli cells expressing or not polysaccharides at their surface. Analysis of measurements obtained under $\mathrm{pH}$ conditions corresponding to distinct electrostatic features of the bacterial envelopes and/or of the NPs makes it possible to decipher the relative contribution of electrostatic interaction forces in the binding of the NPs to the four bacterial strains of interest. We clearly evidence that regardless of the $\mathrm{pH}$ conditions NP adhesion to cells surface is suppressed in the presence of O-antigen glycopolymeric layer whereas the occurrence or not of NP-cell adhesion events closely follows expectations based on electrokinetic results. This work demonstrates that a refined assessment of the interactions between NPs and biological surfaces highly benefits from the joint consideration of electrokinetic measurements, conducted at the NP dispersion and cell population scales, and of AFM-single NP measurements performed at the single cell level. These techniques represent a powerful platform for a rapid identification of the role played by cell surface biomolecules in mediating NP approach to complex and diverse cell wall structures or in governing NP bioadhesion. Possible applications of the here-introduced AFM-single NP force measurement mode include -among others- the evaluation of the first stage of NP toxicity mechanisms within risk assessment strategies. 


\section{Methods}

Bacterial strains. Two types of bacteria are used in this study: the Gram-positive bacterium Lactococcus lactis (strain MG1363) and the Gram-negative bacterium Escherichia coli (K12, strain MG1655). The cell envelope of Gram-negative bacteria features a thin layer of peptidoglycan (PG) overlaid by an outer membrane, in which are anchored LPS covering $75 \%$ of the cell surface. ${ }^{58,59}$ At the opposite, the Gram-positive cell envelope is made of a thick layer of PG crossed by teichoic acids, sometimes covered by an outer layer of polysaccharides. $^{60-62}$ The current work deals with four bacterial strains: E. coli wild type (WT) K-12 M1655 (E. coli genetic stock center \#CGSC6300) that naturally do not produce Oantigen due to the interruption of the $w b b L$ gene by an insertion element (IS), an $E$. coli mutant genetically modified to express O-antigen at their surface by restoring the $w b b L$ gene (denoted E. coli LPS $^{+}$in the manuscript), ${ }^{38}$ L. lactis wild type (WT) MG1363, and an L. lactis mutant devoid of the native surface polysaccharide pellicle (PSP) - VES5748 (hereafter denoted as L. lactis PSP'). ${ }^{39}$

L. lactis strains were grown for $12 \mathrm{~h}$ in $\mathrm{M} 17$ medium supplemented with $0.5 \%$ glucose, at 30 ${ }^{\circ} \mathrm{C}$ without shaking. E. coli strains were grown for $12 \mathrm{~h}$ in Lysogeny Broth (LB) at $37^{\circ} \mathrm{C}$ with shaking at $200 \mathrm{rpm}$.

Carboxylated PAMAM Dendrimers. Half-generation G8.5 carboxylate-terminated poly(amidoamine) (PAMAM) dendrimers dissolved in water were purchased from Dendritech (Dendritech Inc, U.S.A.). They consist of a hyperbranched amino-core which possesses protonable tertiary amine groups and a peripheral shell made of dissociable carboxylic groups. ${ }^{5,24,63}$ Each dendrimer contains $2\left(2^{n+1}-1\right)$ tertiary amine groups and $2^{n+2}$ carboxylic groups, ${ }^{24} n$ being the dendrimer generation with $n=9$ for G8.5 dendrimer generation as adopted in this work (i.e. 2046 tertiary amine and 2048 carboxylic groups). 
Bacterial electrophoretic mobility measurements. The electrophoretic mobility measurements of the bacteria of interest in this work were performed at room temperature using a Zetaphoremeter IV (CAD Instrumentations, Les Essarts le Roi, France). For that purpose, cells were harvested and rinsed twice by centrifugation at $5000 \times \mathrm{g}$ for $2 \mathrm{~min}$, and resuspended in $\mathrm{KNO}_{3}$ (Sigma-Aldrich, purity > 99\%) to a final $\mathrm{OD}_{600 \mathrm{~nm}}$ of $0.4\left(10^{8}\right.$ cells $\left./ \mathrm{mL}\right)$. The cell suspensions were then diluted at an $\mathrm{OD}_{600 \mathrm{~nm}}$ of 0.04 in 1, 5, 10 and $100 \mathrm{mM} \mathrm{KNO}_{3}$ solutions and the solution $\mathrm{pH}$ was adjusted at the desired value ( 3.5 and 6 in this study) after proper addition of $\mathrm{HNO}_{3}(0.1 \mathrm{M}$, Sigma, purum p.a.) and $\mathrm{KOH}(0.1 \mathrm{M}, \mathrm{VWR}$, convol Normadose) solutions. The determination of the mobility consisted in following the displacements of bacteria in a quartz Suprasil ${ }^{\circledR}$ rectangular capillary under conditions where a constant direct-current electric field (around $800 \mathrm{~V} / \mathrm{m}$ ) is applied. Migration of bacteria was measured by tracking the reflection by the bioparticles of a laser beam at a $90^{\circ}$ angle with use of a charge-coupled device camera. Trajectories were recorded in real time and processed with help of an image analysis software, thus making possible evaluation of cells electrophoretic mobilities. For each electrolyte concentration tested, measurements were performed in triplicate. Under all conditions adopted in this work, we found monomodal Gaussian distribution of electrophoretic mobilities as a function of the number of tracked cell trajectories.

Nanoparticles electrophoretic mobility measurements. The electrophoretic mobility of G8.5 PAMAM-COOH dendrimers was measured as a function of $\mathrm{KNO}_{3}$ (Sigma-Aldrich, purity > 99\%) concentration at room temperature using a Zetasizer Nano ZS instrument (Malvern Instruments). Desired $\mathrm{pH}$ values were adjusted by proper addition of $\mathrm{HNO}_{3}(0.1 \mathrm{M}$, Sigma, purum p.a.) and $\mathrm{KOH}(0.1 \mathrm{M}, \mathrm{VWR}$, convol Normadose) solutions. Each reported data point is the average of at least 3 distinct mobility acquisitions. Particle size (of $\sim 4.5 \mathrm{~nm}$ ) was also 
measured (data not shown) with no sign of aggregation under the $\mathrm{pH}$ and salt concentration conditions relevant in this work.

Atomic force microscopy. AFM measurements were performed on an Icon Dimension from Bruker Corporation (Santa Barbara, CA) equipped with an home-made liquid cell in $10 \mathrm{mM}$ $\mathrm{KNO}_{3}$ electrolyte solution at room temperature. Contact mode imaging was adopted using oxide sharpened microfabricated $\mathrm{Si}_{3} \mathrm{~N}_{4}$ cantilevers with a nominal spring constant of $\sim 0.01 \mathrm{~N}$ $\mathrm{m}^{-1}$ (MSCT, Bruker Corporation). Bacteria were immobilized by mechanical trapping into porous polycarbonate membranes (Millipore, Billerica, MA) with a pore size similar to the cell dimension. ${ }^{64}$ After filtering a cell culture, the filter was gently rinsed with the buffer, carefully cut $(\sim 1 \mathrm{~cm} \times 1 \mathrm{~cm})$, attached to a steel sample puck using a small piece of double sided adhesive tape and mounted into the AFM liquid cell without dewetting. Regarding force spectroscopy measurements, bacteria were first localized using a bare tip, and the latter was subsequently replaced by a NP-functionalized tip.

NP-decorated AFM tips were generated upon covalent attachment of PAMAM-COOH dendrimers to the AFM tips. For that purpose, MSCT cantilevers were used and their spring constants (of nominal values $0.03 \mathrm{~N} \mathrm{~m}^{-1}$ ) were accurately determined on the basis of the thermal noise method. In detail, tips were first functionalized with amine groups. To do so, they were washed for 10 min in Piranha solution (3:1 mixture of concentrated $\mathrm{H}_{2} \mathrm{SO}_{4}$ and 30 $\% \mathrm{H}_{2} \mathrm{O}_{2}$ solution), rinsed thoroughly with ultrapure water, dried with $\mathrm{N}_{2}$, and finally rinsed 3 times with chloroform and twice with ethanol, dried and placed in an UV-ozone cleaner for $15 \mathrm{~min}$. Cleaned cantilevers were immersed overnight into an ethanolamine solution (3.3 g of ethanolamine into $6 \mathrm{~mL}$ of DMSO), then washed three times with DMSO and twice with ethanol, and finally dried with $\mathrm{N}_{2}$. The dendrimers were then covalently attached to the tip via N-hydroxysuccinimide (NHS) 1-ethyl-3-(3-dimethylaminopropyl)-carbodiimide (EDC) 
surface chemistry. Dendrimers were immersed in NHS-EDC solution at a concentration allowing 10 out of the 2048 carboxylic surface groups of a dendrimer particle to be activated. To achieve such activation level, $50 \mu \mathrm{L}$ of the dendrimer solution received from the provider $\left(1.06 \times 10^{-4} \mathrm{~mol} \mathrm{~L}^{-1}\right)$ were diluted in $2 \mathrm{~mL}$ ultrapure water containing EDC at 5 $\mathrm{mg} \mathrm{L}^{-1}$ and NHS at $5.6 \mathrm{mg} \mathrm{L}^{-1}$. The amine-decorated tips were then immediately immersed in the activated-dendrimer solution, let for 1 hour, rinsed in ultrapure water and stored in water until use.

Adhesion maps were obtained by recording $32 \times 32$ force-distance curves on $500 \mathrm{~nm} \times 500$ $\mathrm{nm}$ areas of the bacterial surface. All force curves were recorded in $10 \mathrm{mM} \mathrm{KNO}_{3}$ solution with a maximum applied force of $250 \mathrm{pN}$, using a constant approach and retraction speed of $1 \mu \mathrm{ms}^{-1}$

\section{ACKNOWLEDGEMENTS}

This work was supported by the French national programme Ec2CO-Ecodyn/MicrobiEN (TOXSCALE project) and by the CNRS national program PEPS-FaiDoRA (NanodUP project). CB and JMG are supported by the French government's Investissements d'Avenir Program, Laboratoire d’Excellence "Integrative Biology of Emerging Infectious Diseases" (grant nANR10-LABX-62-IBEID) and the Fondation pour la Recherche Médicale grant (Equipe FRM DEQ20140329508). 


\section{REFERENCES}

1. S. Svenson, Eur. J. Pharm. Biopharm., 2009, 71, 445-462.

2. K. Jain, P. Kesharwani, U. Gupta and N. K. Jain, Int. J. Pharm., 2010, 394, 122-142.

3. A. E. Nel, L. Madler, D. Velegol, T. Xia, E. M. V. Hoek, P. Somasundaran, F. Klaessig, V. Castranova and M. Thompson, Nature Materials, 2009, 8, 543-557.

4. D. A. Tomalia, H. Baker, J. Dewald, M. Hall, G. Kallos, S. Martin, J. Roeck, J. Ryder and P. Smith, Polymer Journal, 1985, 17, 117-132.

5. D. A. Tomalia and J. M. J. Frechet, J. Polym. Sci. A Polym. Chem., 2002, 40, 2719-2728.

6. A. M. Caminade, A. Ouali, R. Laurent, C. O. Turrin and J. P. Majoral, Coord. Chem. Rev., 2016, 308, 478-497.

7. W. W. Gao, S. Thamphiwatana, P. Angsantikul and L. F. Zhang, Wiley Interdiscip. Rev. Nanomed. Nanobiotechnol., 2014, 6, 532-547.

8. B. Noriega-Luna, L. A. Godinez, F. J. Rodriguez, A. Rodriguez, G. Z. L. de Larrea, C. F. SosaFerreyra, R. F. Mercado-Curiel, J. Manriquez and E. Bustos, J. Nanomater., 2014, 2014, 507273.

9. M. Selin, L. Peltonen, J. Hirvonen and L. M. Bimbo, J. Drug Deliv. Sci., 2016, 34, 10-20.

10. X. Ming, L. Wu, K. Carver, A. Yuan and Y. Z. Min, Nanoscale, 2015, 7, 12302-12306.

11. N. J. Braun, M. C. DeBrosse, S. M. Hussain and K. K. Comfort, Mat. sci. Eng. C-Mater., 2016, 64, 34-42.

12. P. Foroozandeh and A. A. Aziz, Nanoscale res. lett., 2015, 10, 221.

13. M. Lundqvist, J. Stigler, T. Cedervall, T. Berggard, M. B. Flanagan, I. Lynch, G. Elia and K. Dawson, ACS Nano, 2011, 5, 7503-7509.

14. P. Kesharwani, K. Jain and N. K. Jain, Progress in Polymer Science, 2014, 39, 268-307.

15. F. Ruggeri, A. Akesson, P. Y. Chapuis, C. A. S. Nielsen, M. P. Monopoli, K. A. Dawson, T. G. Pomorski and M. Cardenas, Soft Matter, 2013, 9, 8862-8870.

16. S. H. Lee, S. H. Choi, S. H. Kim and T. G. Park, J. Control. Release, 2008, 125, 25-32.

17. M. Labieniec and T. Gabryelak, Mitochondrion, 2008, 8, 305-312.

18. J. H. Lee, K. E. Cha, M. S. Kim, H. W. Hong, D. J. Chung, G. Ryu and H. Myung, Toxicology Letters, 2009, 190, 202-207.

19. X. J. Cai, R. R. Jin, J. L. Wang, D. Yue, Q. Jiang, Y. Wu and Z. W. Gu, ACS Appli. Mater. Interfaces, 2016, 8, 5821-5832.

20. M. Ionov, A. Ihnatsyeu-Kachan, S. Michlewska, N. Shcharbina, D. Shcharbin, J. P. Majoral and M. Bryszewska, Int. J. Pharm., 2016, 499, 247-254.

21. N. Malik, R. Wiwattanapatapee, R. Klopsch, K. Lorenz, H. Frey, J. W. Weener, E. W. Meijer, W. Paulus and R. Duncan, J. Control. Release, 2000, 68, 299-302.

22. R. Jevprasesphant, J. Penny, R. Jalal, D. Attwood, N. B. McKeown and A. D'Emanuele, Int. J. Pharm., 2003, 252, 263-266.

23. A. Beaussart, C. Caillet, I. Bihannic, R. Zimmermann and J. F. L. Duval, Nanoscale, 2018, 20, 3181-3190.

24. M. Moussa, C. Caillet, R. M. Town and J. F. L. Duval, Langmuir, 2015, 31, 5656-5666.

25. E. Alpaslan, B. M. Geilich, H. Yazici and T. J. Webster, Sci. Rep., 2017, 7, 45859.

26. C. Z. S. Chen and S. L. Cooper, Biomaterials, 2002, 23, 3359-3368.

27. Z. V. Feng, I. L. Gunsolus, T. A. Qiu, K. R. Hurley, L. H. Nyberg, H. Frew, K. P. Johnson, A. M. Vartanian, L. M. Jacob, S. E. Lohse, M. D. Torelli, R. J. Hamers, C. J. Murphy and C. L. Haynes, Chem. Sci., 2015, 6, 5186-5196.

28. K. A. Heys, M. J. Riding, R. J. Strong, R. F. Shore, M. G. Pereira, K. C. Jones, K. T. Semple and F. L. Martin, Analyst, 2014, 139, 896-905.

29. H. D. Lu, S. S. Yang, B. K. Wilson, S. A. McManus, C. Chen and R. K. Prud'homme, Appl. Nanosci., 2017, 7, 83-93. 
30. N. S. Abadeer, G. Fulop, S. Chen, M. Kall and C. J. Murphy, ACS Appli. Mater. Interfaces, 2015, 7, 24915-24925.

31. K. H. Jacobson, I. L. Gunsolus, T. R. Kuech, J. M. Troiano, E. S. Melby, S. E. Lohse, D. Hu, W. B. Chrisler, C. J. Murphy, G. Orr, F. M. Geiger, C. L. Haynes and J. A. Pedersen, Environ. Sci. Technol., 2015, 49, 10642-10650.

32. W. Jiang, K. Yang, R. W. Vachet and B. S. Xing, Langmuir, 2010, 26, 18071-18077.

33. C. Yang, H. Xie, Q. C. Li, E. J. Sun and B. L. Su, J. Colloid Interface Sci., 2015, 450, 388-395.

34. M. A. Ansari, H. M. Khan, A. A. Khan, S. S. Cameotra, Q. Saquib and J. Musarrat, J. Appl. Microbiol., 2014, 116, 772-783.

35. P. T. Wong, S. Z. Tang, K. Tang, A. Coulter, J. Mukherjee, K. Gam, J. R. Baker and S. K. Choi, J. Mater. Chem. B, 2015, 3, 1149-1156.

36. G. Francius, P. Polyakov, J. Merlin, Y. Abe, J. M. Ghigo, C. Merlin, C. Beloin and J. F. L. Duval, Plos One, 2011, 6, e20066.

37. A. Beaussart, M. Abellan-Flos, S. El-Kirat-Chatel, S. P. Vincent and Y. F. Dufrene, Nano Lett., 2016, 16, 1299-1307.

38. O. Rendueles, C. Beloin, P. Latour-Lambert and J. M. Ghigo, ISME J., 2014, 8, 1275-1288.

39. M. P. Chapot-Chartier, E. Vinogradov, I. Sadovskaya, G. Andre, M. Y. Mistou, P. Trieu-Cuot, S. Furlan, E. Bidnenko, P. Courtin, C. Pechoux, P. Hols, Y. F. Dufrene and S. Kulakauskas, J. Biol. Chem., 2010, 285, 10464-10471.

40. G. Andre, S. Kulakauskas, M. P. Chapot-Chartier, B. Navet, M. Deghorain, E. Bernard, P. Hols and Y. F. Dufrene, Nat. Commun., 2010, 1, 27.

41. C. Morlot, A. Zapun, O. Dideberg and T. Vernet, Mol. Microbiol., 2003, 50, 845-855.

42. A. Touhami, M. H. Jericho and T. J. Beveridge, J. Bacteriol., 2004, 186, 3286-3295.

43. J. F. L. Duval and F. Gaboriaud, Curr. Opin. Colloid Interface Sci., 2010, 15, 184-195.

44. F. Gaboriaud, E. Dague, S. Bailet, F. Jorand, J. Duval and F. Thomas, Colloids Surf. B, 2006, 52, 108-116.

45. P. Veiga, M. Erkelenz, E. Bernard, P. Courtin, S. Kulakauskas and M. P. Chapot-Chartier, J. Bacteriol., 2009, 191, 3752-3757.

46. N. E. Kramer, H. E. Hasper, P. T. C. van den Bogaard, S. Morath, B. de Kruijff, T. Hartung, E. J. Smid, E. Breukink, J. Kok and O. P. Kuipers, Microbiology, 2008, 154, 1755-1762.

47. L. Sijtsma, J. T. M. Wouters and K. J. Hellingwerf, J. Bacteriol., 1990, 172, 7126-7130.

48. Y. Q. Hong and P. R. Reeves, J. Bacteriol., 2014, 196, 1713-1722.

49. C. Capodici, S. Chen, Z. Sidorczyk, P. Elsbach and J. Weiss, Infect. Immun., 1994, 62, 259-265.

50. S. V. Zubova, A. Y. Ivanov and I. R. Prokhorenko, Microbiology, 2008, 77, 293-297.

51. R. R. Boyer, S. S. Sumner, R. C. Williams, K. E. Kniel and J. M. McKinney, Int. J. Food Microbiol., 2011, 147, 228-232.

52. M. M. Domingues, P. M. Silva, H. G. Franquelim, F. A. Carvalho, M. Castanho and N. C. Santos, Nanomedicine, 2014, 10, 543-551.

53. M. U. Hammer, A. Brauser, C. Olak, G. Brezesinski, T. Goldmann, T. Gutsmann and J. Andra, Biochem. J., 2010, 427, 477-488.

54. A. Kumar, D. Mallik, S. Pal, S. Mallick, S. Sarkar, A. Chanda and A. S. Ghosh, FEMS Microbiol. Lett., 2015, 362, fnv112.

55. V. Dupres, F. D. Menozzi, C. Locht, B. H. Clare, N. L. Abbott, S. Cuenot, C. Bompard, D. Raze and Y. F. Dufrene, Nat. Methods, 2005, 2, 515-520.

56. S. El-Kirat-Chatel and A. Beaussart, In Nanotechnology to Aid Chemical and Biological Defense, ed. T. A. Camesano, 2015, 1-15.

57. I. Sadovskaya, E. Vinogradov, P. Courtin, J. Armalyte, M. Meyrand, E. Giaouris, S. Palussiere, S. Furlan, C. Pechoux, S. Ainsworth, J. Mahony, D. van Sinderen, S. Kulakauskas, Y. Guerardel and M. P. Chapot-Chartier, Mbio, 2017, 8, e01303-17.

58. J. W. Costerton, J. M. Ingram and K. J. Cheng, Bacteriol. Rev., 1974, 38, 87-110.

59. A. P. Le Brun, L. A. Clifton, C. E. Halbert, B. H. Lin, M. Meron, P. J. Holden, J. H. Lakey and S. A. Holt, Biomacromolecules, 2013, 14, 2014-2022. 
60. M. P. Chapot-Chartier and S. Kulakauskas, Microb. Cell Fact., 2014, 13, (Suppl 1):S9.

61. J. Delcour, T. Ferain, M. Deghorain, E. Palumbo and P. Hols, Anton. Leeuw. Int. J. G., 1999, 76, 159-184.

62. C. Weidenmaier and A. Peschel, Nat. Rev. Microbiol., 2008, 6, 276-287.

63. Y. H. Niu, L. Sun and R. A. Crooks, Macromolecules, 2003, 36, 5725-5731.

64. G. Andre, K. Leenhouts, P. Hols and Y. F. Dufrene, J. Bacteriol., 2008, 190, 7079-7086.

\section{FIGURE CAPTIONS}

Fig. 1. Atomic force microscopy-based imaging of living bacteria mechanically trapped in porous membranes. Deflection images recorded in $10 \mathrm{mM} \mathrm{KNO}_{3}$ solution for E. coli WT (a), E. coli modified to express O-antigen (E. coli LPS $^{+}$; b), WT L. lactis (c) and L. lactis mutant devoid of surface polysaccharides pellicle (L. lactis PSP'; d). White and red arrows in $(c, d)$ indicate the division septum and ring-like structures, respectively. White boxes correspond to the areas where the roughness was measured.

Fig. 2. Electrokinetic properties of the bacterial strains. Electrophoretic mobility of $E$. coli WT (red symbols), E. coli LPS $^{+}$(black symbols), WT L. lactis (blue symbols) and L. lactis PSP (green symbols) as a function of $\mathrm{KNO}_{3}$ concentration at $\mathrm{pH} 6.0$ (a) and $\mathrm{pH} 3.5$ (b). The shaded areas indicate the electrolyte concentration at which AFM measurements were performed.

Fig. 3. Electrokinetic properties of dendrimer nanoparticles. Electrophoretic mobility of G8.5 PAMAM- $\mathrm{POOH}$ dendrimers as a function of $\mathrm{KNO}_{3}$ electrolyte concentration at $\mathrm{pH} 6.0$ (blue symbols) and 3.5 (red symbols). Experimental data are represented by points, whereas dotted and solid lines correspond to theoretical modeling extensively detailed in ${ }^{23}$. Adapted from Ref ${ }^{23}$ with permission from The Royal Society of Chemistry.

Fig. 4. Schematics of single-NP force spectroscopy measurements. (a) Carboxylateterminated poly(amidoamine) (PAMAM) dendrimers of generation 8.5 -consisting of secondary and protonable tertiary amine groups located at the branching points of the 
particle core (green circles) and dissociable carboxylic groups that terminate each branch of the structure (orange circles)- are grafted on AFM tips using amino-carboxylate linking chemistry. Force measurements are recorded under liquid conditions at the surface of a living bacterium. For that purpose, a virtual mesh of $32 \times 32$ pixels (b) is defined at the microbial surface. At each pixel, the tip is approached to (blue arrow in a) and retracted from (black arrow in a) the biosurface, resulting in a force distance curve composed of an approach (blue curve in c) and a retraction regime (black curve in c).

Fig. 5. Single-NP force spectroscopy reveals no adhesion between PAMAM-COOH nanoparticles and bacteria at pH 6.0. Adhesion force maps (500 nm $\times 500 \mathrm{~nm}$ ) and adhesion force histograms with representative force-distance curves (blue: approach curves; black: retract curves) obtained by recording spatially resolved force curves using dendrimerdecorated tips at the surface of WT L. lactis (a), L. lactis PSP' (b), E. coli WT (c) and E. coli LPS $^{+}$ (d) ( $n=1024$ curves for each cell). Grey scales on the maps correspond to 0-100 pN range, black pixels corresponds to the absence of adhesion event. The green and red colors in the histograms at the right side correspond to two independent experiments.

Fig. 6. NP-bacteria interactions features at pH 3.5. Adhesion force maps ( $500 \mathrm{~nm} \times 500 \mathrm{~nm})$ and adhesion force histograms with representative force-distance curves (blue: approach curves; black: retract curves) obtained by recording spatially resolved force curves using dendrimer-decorated tips at the surface of WT L. lactis (a), L. lactis PSP' (b), E. coli WT (c) and E. coli LPS $^{+}$(d) ( $n=1024$ curves for each cell). Grey scales on the maps correspond to 0-100 $\mathrm{pN}$ range, black pixels corresponds to the absence of adhesion event. The green and red colors in the histograms at the right side correspond to two independent experiments. 